\title{
Interseçóes da música cênica, da voz e da percussão múltipla: um olhar nas obras Toucher (Vinko Globokar), Mitos Brasileiros (Ney Rosauro) e $A$ Dois (Tim Rescala)
}

\author{
Aquim Almeida, Cecilia Tamplenizza \\ Orcid: 0000-0003-1292-262X | Orcid: 0000-0003-2699-7315 \\ Universidade Federal da Bahia
}

\begin{abstract}
Resumo: Esse artigo aborda uma breve introdução sobre as inovaçóes que o século XX reservou para a cena percussiva. Dentre essas inovaçóes, estão: o advento da percussão múltipla, a música cênica para percussão e a utilização da voz, dentre outras. Essas inovaçóes foram influenciadas pelas vanguardas artísticas, experiências que redefiniram a atuação e as possibilidades musicais e cênicas do músico percussionista. Esses aspectos são aqui discutidos a partir de uma breve exemplificação das obras Toucher (1973) de Vinko Globokar, Mitos Brasileiros (1988) de Ney Rosauro e A Dois (1992) de Tim Rescala. Nosso objetivo é estimular o performer percussionista a ampliar o repertório de escolhas performativas no processo de preparo da sua performance.

Palavras-chave: Performance de percussão; Percussão múltipla; Música cênica para percussão; Voz.

Intersecciones de la música escénica, la voz y la percusión múltiple: una mirada de las obras Toucher (Vinko Globokar), Mitos Brasileiras (Ney Rosauro) y A Dois (Tim Rescala)
\end{abstract}

Resumén: Este artículo ofrece una breve introducción a las innovaciones que el siglo XX ha reservado para la escena de la percusión. Entre estas innovaciones se encuentran: el advenimiento de la percusión múltiple, la música escénica para percusión y el uso de la voz, entre otras. Estas innovaciones fueron influenciadas por las vanguardias artísticas, experiencias que redefinieron la interpretación y las posibilidades musicales y escénicas del percusionista. Estos aspectos se discuten aquí a partir de un breve ejemplo de las obras Toucher (1973) de Vinko Globokar, Mitos Brasileiros (1988) de Ney Rosauro y A Dois (1992) de Tim Rescala. Nuestro objetivo es animar al percusionista a ampliar el repertorio de opciones performativas en el proceso de preparación de su interpretación.

Palabras clave: Interpretación de percusión; Percusión múltiple; música escénica para percusión; Voz.

\section{Intersections of scenic music, voice and multiple percussion: a look at Toucher (Vinko Globokar), Mitos Brasileiros (Ney Rosauro) and A Dois (Tim Rescala)}

Abstract: This article covers a brief introduction to the innovations that the 20th century has reserved for the percussive scene. Among these innovations are: the advent of multiple percussion, scenic music for percussion and the use of voice, among others. These innovations were influenced by artistic vanguards, experiences that redefined the performance and musical and scenic possibilities of the percussionist musician. These aspects are discussed here from a brief example of the works Toucher (1973) by Vinko Globokar, Mitos Brasileiros (1988) by Ney Rosauro and A Dois (1992) by Tim Rescala. Our goal is to encourage the percussionist performer to expand the repertoire of performative choices in the process of preparing his performance.

Keywords: Percussion performance; Multiple percussion; Scenic music for percussion; Voice. 


\section{Inoratasio $_{\text {nat }}$}

O repertório escrito para percussão iniciado a partir dos anos de 1930 é um campo de experimentação muito variado, seja do ponto de vista da produção do som, da organologia, da performance ou da atuação dos músicos. Esse repertório é considerado fundamental para o estudo da percussão contemporânea ${ }^{1}$, de suas técnicas e das diferentes possibilidades que o corpo do músico pode desenvolver na sua performance.

A partir desse período, os gestos do percussionista são explorados como elementoschave de sua apresentação. Para além de musicais, os gestos do instrumentista se tornam cênicos, assim como sua voz que é explorada por seus efeitos musicais e percussivos, bem como, por sua dramatização. A partir da segunda metade do século XX, cresce significativamente o número de obras escritas para grupo de percussão ${ }^{2}$, que associam música e teatro. Essa combinação marca um caminho diferente dos gêneros do teatro musical e da ópera, por exemplo, e se propóe como um outro estilo musical que chamamos aqui de música cênica para percussão e que definiremos mais adiante.

Segundo Navas (2016), a associação entre música para percussão e outras artes, como o teatro, levou a ampliaçáo do conceito de percussionista para aquele de músico multifacetado, um performer que adota as técnicas cênicas, do movimento no espaço, da iluminação, do gesto e do uso da voz com o objetivo de transformá-las em instrumento de percussão.

Cabe lembrar que, entre os séculos XIX e XX, observa-se uma gradual expansão do conceito de música ocidental, com a inclusão de diversas possibilidades sonoras, a criação ou adoção de instrumentos que não eram usuais na percussão clássica. Sons, que até então eram considerados ruídos e outros jamais ouvidos, são incorporados às composiçóes. Instrumentos idealizados por culturas e países distantes também são introduzidos nessas obras.

Esses são alguns dos elementos musicais que levaram os compositores a se dedicarem ao repertório percussivo contemporâneo, se tornando este um rico laboratório de experimentação. Segundo Navas (2016, p. 18) outras razóes musicais foram "o surgimento do dodecafonismo e novas escalas, o Movimento Futurista, a experimentaçáo sonora com musique concrète ${ }^{3}$, a aleatoriedade, entre outras"; e Segundo Facchin (2014, p. 29) "as combinaçóes ritmo/timbre, som/efeitos, além da atenção voltada para os timbres sonoros e para as técnicas dos instrumentos extra europeus do mundo inteiro" ${ }^{\text {". }}$.

1 "Entendendo a "percussão contemporânea" como aquela que saiu do fundo das orquestras sinfônicas, no início do século XX, e veio para a boca de cena, tratada como um instrumento solista” (TULLIO, 2014, p. 19).

2 Na tradição musical ocidental, o surgimento de grupos de percussão é datado entre os anos de 1930 e 1940. Esses conjuntos são considerados uma novidade, pois se constituem como uma nova modalidade de música de câmara, abrindo o campo para novas composiçôes escritas somente para percussão. As primeiras composiçôes reconhecidas para grupo de percussão são as Rítmica No 5 e Rítmica No 6, escritas em 1930, pelo compositor cubano Amadeo Roldán. Elas fazem uso de tímpanos, bumbos sinfônicos e outros instrumentos de origem indígena. Rítmica No 5 foi escrita para 11 percussionistas que tocam 13 instrumentos e Rítmica No 6 para 11 percussionistas que tocam 11 instrumentos. Outra obra reconhecida por ser pioneira nesse gênero é Ionisation de Edgar Varèse, de 1931, escrita para 13 percussionistas e 37 instrumentos, entre eles um pianoforte, que pela primeira vez é usado como instrumento de percussão não melódico, ou seja, percutindo sua caixa de ressonância.

3 Música concreta (Tradução nossa).

4 "Combinazioni ritmo/timbro, suono/effetti, oltre che per la particolare attenzione rivolta alle timbriche sonore e alle tecniche degli strumenti extraeuropei di tutto il mondo" (Traduçáo nossa). 
Mas existem também razões sócio-culturais, como a Segunda Revolução Industrial, "a influência da industrialização e da modernização das cidades" (TULLIO, 2014, p. 21), as guerras mundiais, a consequente transformação do pensamento sobre humanidade, uma extensa reflexão filosófica e sociológica sobre o homem contemporâneo e o papel das artes.

Em uma época de grandes contrastes, a industrialização e a modernização revolucionaram a vida das cidades e foram transformando o gosto e a percepçáo humana. Durante a Segunda Revolução Industrial foram inventadas e desenvolvidas novas tecnologias, materiais sintéticos e metais, novas fontes de energia, que ofereceram aos artistas a possibilidade de inovar técnicas e instrumentos (KLINGENDER, 1972; SCHAFER, 2001).

O grande estudo sobre som, efeitos e organologia levou à ampliaçáo do número de instrumentos utilizados pelos percussionistas e à maneira de utilizaçáo dos instrumento como "percussão multipla", dispostos como unidade. Para Schick (2006, apud TULLIO; SULPÍCIO, 2016, p. 2) "um instrumento de percussão múltipla consiste em uma série de instrumentos individuais arranjados de tal maneira que um percussionista possa tocar todos como uma "unidade poli instrumental singular".

Em 1918, Stravinsky compôs a obra A História do Soldado, que foi estreada no mesmo ano. Escrita para sete instrumentistas, além do regente e quatro atores, a obra foi revolucionária no campo do repertório para percussão, por, pela primeira vez, utilizar uma montagem de percussão múltipla, unindo diversos instrumentos da percussão - caixa-clara, bumbo, pandeiro, triângulo, entre outros - para a execução quase que simultânea por apenas um instrumentista. Diversos autores especulam que o motivo para essa inovação se deu por conta da crise econômica que estavam passando, dando possibilidade de apenas um percussionista viajar em turnês, etc.

Outros compositores foram influenciados por essa inovação e seguiram criando possibilidades de unir diversos instrumentos para serem executados por apenas uma pessoa. Amadeo Roldán e Edgard Varése, por exemplo, foram pioneiros em escrever as primeiras obras para grupo de percussão, com executantes tocando mais de um instrumento.

Nesse artigo temos como objetivo principal refletir as interseçóes entre a percussão múltipla, música cênica e a voz, exemplificando trechos de obras relevantes do repertório percussivo. No específico nos dedicamos às peças Toucher (1973) de Vinho Globkar, Mitos Brasileiros (1988) de Ney Rosauro e A Dois (1992) de Tim Rescala. No entanto, antes nos cabe aprofundar sobre o gênero da música cênica e a sua exploraçáo no repertório escrito para percussão do século XX.

\section{A influência do teatro no repertório percussivo contemporâneo: o caso da música cênica}

A partir do começo do século XX, a relação milenar entre os instrumentos de percussão e o teatro ganhou um novo olhar com o surgimento das vanguardas artísticas, especialmente com o Dadaísmo e o Surrealismo, que levaram ao surgimento do 'Teatro Instrumental's, com obras que póem o acento nos aspectos teatrais da música e nas capacidades cênicas dos instrumentistas. As obras teatrais de autores como Artaud, Pirandello,

5 O Teatro Instrumental teve desdobramentos no movimento da performance surrealista, o Teatro do Absurdo, nascido na Europa também na segunda metade do século XX. Para Barber (apud NAVAS, 2016, p. 42) "o Teatro Instrumental náo se compóe para um instrumento, mas para um instrumentista [...] com olhar crítico e com reserva imaginativa para encontrar soluçôes técnicas próprias.

ICTUS Music Journal vol. 15 n.2 
Brecht produzidas no começo do século XX, empreendem uma desconstruçáo dos elementos principais do teatro clássico, a ação e o diálogo, mostrando quanto a renovação entre música e teatro era propícia nessa época.

Com o surgimento do Teatro Instrumental foi se consolidando um novo estilo de performance musical que chamamos aqui de 'Música Cênica' ${ }^{6}$, conhecido também por outros termos como 'Música-Teatro', que explora possibilidades musicais e teatrais como sendo uma unidade. Um novo gênero, que não tem nada a ver com a ópera, com o teatro musical ou com outras formas populares de teatro musicado, mas um estilo que mistura a música, o texto e a expressão cênica através da performance do instrumentista. "Um repertório fora da tradição operística, no qual o drama pertence e é encenado tanto pelos instrumentistas quanto pelos cantores (SERALE, 2009; apud NAVAS, 2016, p. 40).

A partir desse momento, se define a ideia de um performer/músico/percussionista capaz de atuar no palco a partir de diversas habilidades, não somente as instrumentais (NAVAS, 2016). O percussionista é chamado para incorporar elementos da corporeidade, além das funções comuns de tocar e interpretar o repertório, incluindo em suas apresentações elementos cênicos e vocais. A área solística da percussão tem sido um grande âmbito de experimentação sobre esse tema (NAVAS, 2016; ZORZETTO, 2016).

O compositor argentino Mauricio Kagel (1931-2008) é, segundo Navas, um personagem central no estudo e desenvolvimento do 'Teatro Instrumental', sendo seu expoente mais determinante e influente. Segundo Griffiths (apud NAVAS, 2016, p. 40), as suas obras requerem "técnicas insólitas, gritantes deformações de interpretação, o uso de instrumentos incomuns e assim por diante, sempre visando efeitos não só musicais, mas visuais e dramáticos". Esses elementos, segundo Navas (2016), exige do performer o desenvolvimento de habilidades extramusicais, explorando outras capacidades de performáticas.

De acordo com Navas (2016), que desenvolveu uma dissertação sobre a atuação multifacetada do percussionista, as décadas de 60 e 70 foram centrais na fase de exploração do potencial cênico e performativo da música e da atuação do instrumentista.

O compositor americano John Cage (1912-92) é considerado referência na música teatral de vanguarda na segunda metade do século XX. O indeterminismo e o acaso na composição e interpretação, o happening (com a participaçáo do público tendo aspecto importante), a utilização de objetos incomuns como instrumentos, a criação do piano preparado e a exploraçáo do silêncio (4'33') entre outros, indicam o início de uma nova fase na história

6 Em sua dissertação sobre música cênica no repertório de percussão contemporânea, Martins (2015, p. 2) destaca a importância de o termo adotado deixar claro que se trata de um evento musical, "'música cênica', por exemplo: deixa bem claro essa hierarquia dos eventos, pois com o termo "música" em primeiro lugar entende-se que se trata de um evento musical e, depois, o termo "cênica" faz compreender que este evento musical é acompanhado de açóes cênicas". Para Martins (2015) a importância dos aspectos musicais nesse tipo de repertório se dá, pois, apesar de incluir aspectos cênicos em sua performance, o músico continua sendo músico, tocando em orquestras, com grupos de música de câmara ou como solista de um repertório mais tradicional, sem ter a necessidade de que este músico atue como ator ou como dançarino. Por tanto, o instrumentista, nesse caso o percussionista, "adquire uma amplitude no seu leque de açóes artísticas, incorporando a capacidade de também atuar, cantar e dançar ao mesmo tempo em que toca, quando isso está sendo solicitado na partitura" (MARTINS, 2015, p. 6).

7 Quem, para se referir a essas composições, opta pelo uso do termo 'Música-Teatro' pretende, através do hífen, aproximar ainda mais esses dois diferentes objetos de estudo, tornando-os um objeto único. O central dessas performances seria, portanto, não apenas juntar as diversas técnicas artísticas, mas criar uma nova obra em que as diferentes linguagens deveriam ter, segundo Salzman e Dési (2008; apud ZORZETTO, 2016, p. 19), "algum tipo de igualdade" entre elas. 
da música, abrindo novos pensamentos acerca da relação entre música, som e teatro (NAVAS, 2016, p. 39).

A partir dos anos de 1950, lembra Glusberg (2013, p. 26), as teorias de Duchamp, os manifestos de Tzara, as contribuiçóes de Stanivlasky, Dullin, Baty e Piscator, bem como os escritos de Artaud retomaram o interesse dos artistas. E são nesses anos que o repertório de música cênica ganha importância. Através dessas composições, a atuação do músico se expande e se enriquece com diversas técnicas e linguagens artísticas, como a poesia, o canto e o teatro.

$\mathrm{O}$ performer não se foca apenas no seu instrumento. Em algumas composiçóes, o próprio corpo do percussionista se torna um instrumento, em outras, a pesquisa e a criaçáo instrumental são centrais na execução das peças. Em ambos os casos, a procura de como executar um som, seja através das possibilidades sonoras do corpo humano, ou de qualquer outro material que pode ser usado e incluído no et $^{8}$ de instrumentos musicais usados nestes tipos de espetáculos, se torna central. "Existem obras onde o performer precisa cantar, falar, gritar, dançar até usar uma roupa específica, abrindo assim as portas para um gênero novo, onde a música e o teatro tornam-se um só" (NAVAS, 2016, p. 40).

O movimento é um dos elementos centrais dessas composiçóes. Segundo Martins (2015, p. 6), o meio acadêmico musical percussivo se demonstrou sempre bastante interessado "no estudo dos seus movimentos, pois o gestual tem íntima relaçáo com o movimento técnico do intérprete e com as respostas sonoras obtidas". A autora propóe que as discussōes sobre gesto e movimento na percussão podem beneficiar a música cênica, invertendo mais uma vez a ideia inicial de associação entre gesto, teatro e música. Desde essa perspectiva, seria o gesto musical a ser transformado em gesto cênico e não o contrário. Segundo Serale (apud MARTINS, 2015, p. 8), a ideia fundamental da música cênica é que a performance musical por si só é dramática: "o solista em cena, vestido para o concerto, tocando sobre o palco e toda ação musical não deixa de ser uma açáo cênica”. Porém, nem toda ação cênica trata-se de uma açáo musical. A música cênica se aprofunda nesse conceito.

Em sua dissertação sobre percussão e voz na música-teatro, Zorzetto (2016, p. 20) discorre sobre música cênica como um subgênero:

Segundo Hansen, é uma disciplina da performance que pode combinar todas as formas de arte, a partir de uma estrutura que abranja os dois componentes contidos na sua própria grafia: música e teatro, além de iluminaçáo, cenografia, figurinos, pintura, artes plásticas etc. Ou seja, uma mistura de três artes: a musical, a teatral e a visual.

Assistir a um espetáculo desse gênero não deve proporcionar apenas um estímulo sonoro ou visual, mas deve proporcionar uma experiência, advinda de uma ambiência cênica. Segundo Barber (1987; apud NAVAS, 2016, p. 40) se referindo à música-teatro: "luzes, objetos, palavras, movimentos e instrumentos sáo articulados e compostos como se fossem sons, timbres e tempos. São música na mesma medida em que a música se tornou outra coisa".

Vamos agora fazer uma análise da peça Toucher do compositor, diretor e trombonista franco-esloveno Vinko Globokar, procurando sublinhar como acontece o entrelaçamento entre música e teatro em seu trabalho. Vamos também refletir sobre como a percussão múltipla é adotada para compor essa experiência, que é ao mesmo tempo cênica e musical. 


\section{Toucher (1973) de Vinko Globokar}

V inko Globokar (1934-), francês, começou sua formaçáo musical e carreira como músico de jazz. Além disso, estudou trombone, música de câmara, composição e regência, contraponto com professores como Leibowitz, Hodeir, Berio, entre outros. Estreou diversas obras para trombone de Luciano Berio, Mauricio Kagel, Karlheinz Stockhausen, René Leibowitz, por exemplo. Em 2003, foi nomeado membro honorário da ISCM, International Society for Contemporary Music (RICORDI, 2009).

Nas composiçóes de Globokar podemos sublinhar as seguintes características: utilização de técnicas não convencionais e estendidas; ponto de vista crítico da tradição musical ocidental; espontaneidade e criatividade ligada aos seus estudos sobre improvisaçáo livre; e compreensão política da música (MARTINS, 2015, p. 43-44).

A obra de Globokar que apresentamos aqui, Toucher, exemplifica bem algumas das mais exploradas ideias do compositor inerentes à interseção entre música e teatro. Entre elas, nos referimos a reflexões sobre o palco, não como um espaço teatral, onde através de uma mise-en-scéne e uma dramaturgia se encena uma outra realidade ou uma ilusão de realidade, mas ligado às ideias do simbolismo conceitual exploradas pela Performing Art.

Para Quitt (2009, p. 35) Globokar baseia sua obra "na amálgama dos elementos performáticos com as formas da representação simbólica", de maneira que inclusive o conteúdo extramusical se torna uma ferramenta para a escrita musical. $\mathrm{O}$ autor também afirma que "a música não deve descrever o conteúdo, mas deve oferecer uma espécie de espelho estrutural dele"10. Mesmo em uma obra como Toucher, podemos observar essa caraterística. Apesar de constar no subtítulo a palavra 'narrador', na performance o ato narrativo interessa por sua funçáo musical e política. Toucher é uma composição de 1973, em que o músico, de fato, narra trechos da peça $A$ Vida de Galileu Galilei (1938) de Bertolt Brecht (1898-1956) enquanto toca um set de percussão múltipla. A obra de Brecht narra a vida de Galileu Galilei (1564-1642) e de sua luta para comprovar o sistema solar proposto por Copérnico, que descartava a centralidade da terra no universo, rediscutindo muitas questóes filosóficas, religiosas, políticas e científicas do século XVII. A obra se concentra principalmente no período em que Galilei sofreu os processos de inquisição e abjura.

Na obra de Globokar, o performer não narra para contar uma história, mas para expor ao espectador um questionamento político. "Uma obra baseada em outra obra de cunho político-social, e escrita por um autor teatral renomado pelo seu envolvimento político, evidencia como o compositor se envolve e compóe pensando em questóes políticas", escreve Martins $(2015$, p.46).

A unidade narrativa da peça de Brecht não é mantida por Globokar, que muda o roteiro, reestruturando cenas e misturando personagens. Em alguns momentos, a própria verbalização do texto é voluntariamente distorcida chegando a se perder o sentido das palavras e das frases. Fonemas, palavras e frases são pensados como materiais de pesquisa e de experimentação sobre voz como instrumento, sobre ação cênica e vida no palco.

$9 \quad$ "Like Performance Art, it rests on the amalgamation of performative elements with forms of symbolic representation" (Tradução nossa).

10 "Music should not describe content, but should offer a kind of structural mirror of it" (Tradução nossa). 
A obra, com texto em francês, é dividida em seis cenas intercaladas por intermezzo musical e silêncios. A primeira cena se desvincula da peça de Brecht, introduzindo ao espectador o principal aspecto político da emissão vocal do percussionista: o corpo em cena como instrumento. O músico apresenta sons vocais e silábicos e, em seguida, os imita por meio de sons emitidos pelos instrumentos percussivos. Com essa introdução, o performer apresenta os instrumentos da sua montagem de percussão múltipla e expóe ao público as suas escolhas, pois há um jogo imitativo entre os sons produzidos com a voz, as sílabas francesas que se repetem durante a execução do espetáculo e os que são reproduzidos com a percussão (Exemplo 1).

Exemplo 1: Recorte da primeira página da partitura da obra Toucher onde percebemos as instruçôes para a introdução da obra e para a primeira cena (GLOBOKAR, 1972).

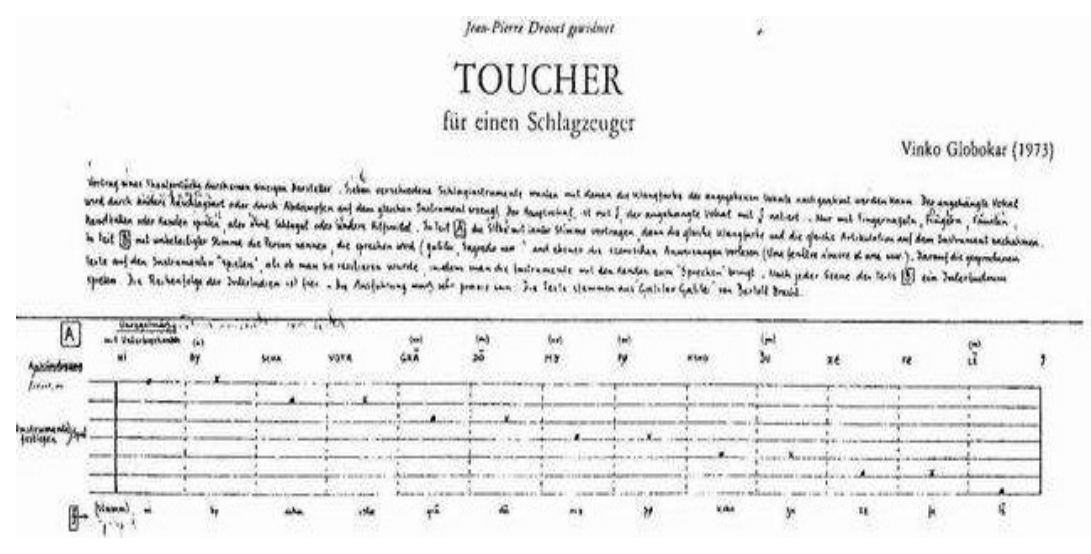

A cena se apresenta como uma afinação dos instrumentos/vozes e de reflexão sobre o corpo do músico expandido pelas escolhas instrumentais. Vale ressaltar que Globokar não define na partitura quais instrumentos devem ser utilizados, deixando ao performer a liberdade de escolha, como podemos perceber nas figuras a seguir.

Figura 1: Performance de Jean-Pierre Drouet (MORIN, 2016) ${ }^{11 .}$

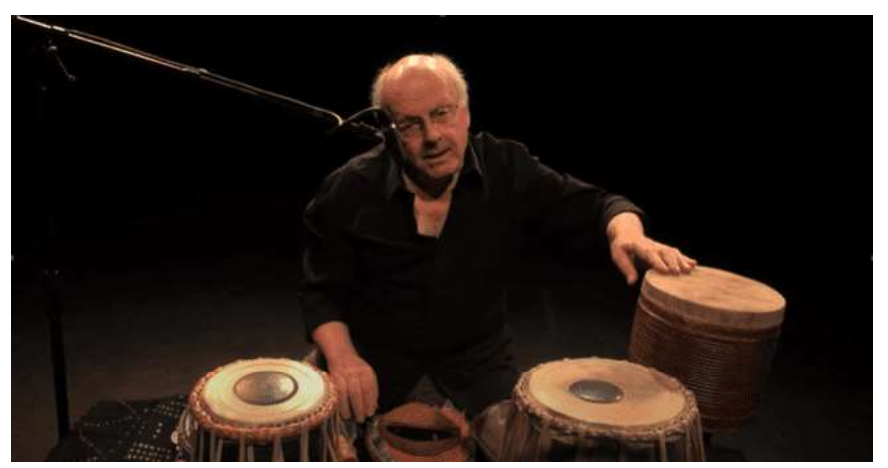

11 “Jean-Pierre Drouet performing Globokar and Aperghis". Disponível em: https://www.youtube. com/watch?v=XbsXAgIuTm0\&t=360s (MORIN, 2016). Acesso 25 fev 2021. 
Figura 2: Performance de Nath Calan (CALANDRIN, 2015) ${ }^{12}$

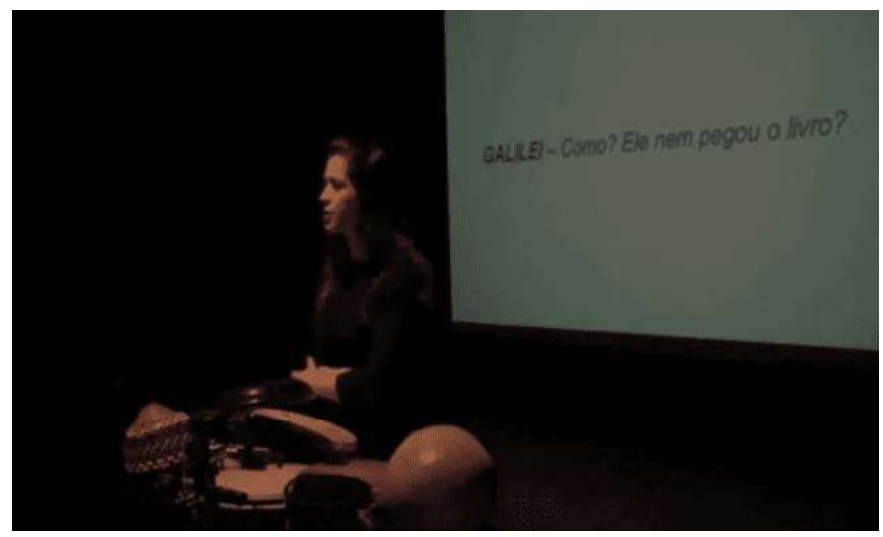

Figura 3: Performance de Caleb Herron (PercussionCaleb, 2010) ${ }^{13}$

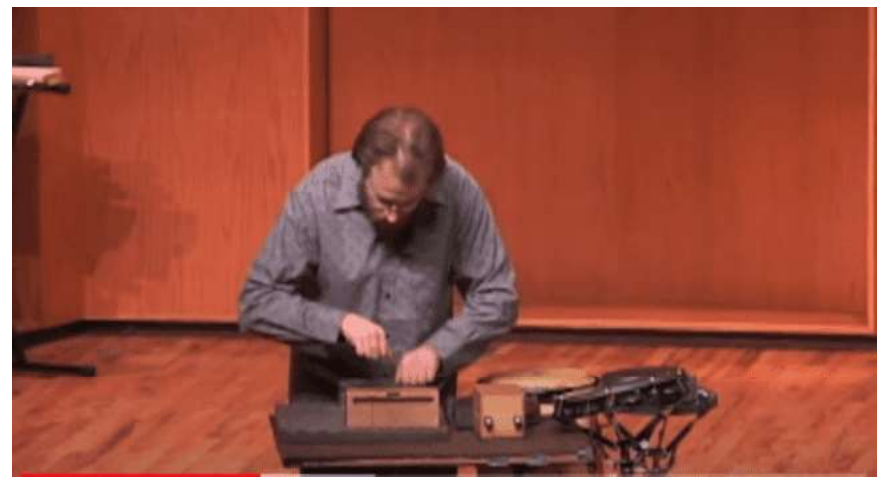

Globokar não dá informaçóes sobre ritmo, andamento e alturas na execução das palavras, ausência que resulta na liberdade e personalização da pesquisa percussiva vocal de cada performer. Há também certa margem de liberdade quanto à performance teatral, aos gestos. Em alguns casos, Globokar indica se a cena deve ser executada em voz audível ou de forma quase inaudível. Há cenas em que a voz é muda e se manifesta como gesto mímico ou dublagem, criando o efeito que o músico está falando através dos instrumentos.

Podemos perceber, nas figuras anteriores, diferentes montagens de percussão múltipla, com instrumentaçóes diversas, por isso, para uma sílaba, cada performer poderá selecionar um instrumento diferente para representá-la, como por exemplo: as sílabas "By" e "Votr", que sáo representadas, seguindo a ordem das figuras acima, pelos instrumentos: pandeiro e uma espécie de inchada no início e dois toques em um instrumento de madeira (Figura 1); tamborim e cabaça do xequerê (Figura 2); e wood block e cowbell (Figura 3).

Ao longo de toda a composiçáo, a voz do percussionista é explorada pelos diferentes sons e ruídos que é capaz de emitir fazendo ressoar consoantes, vogais e fonemas franceses. Globokar chama o uso da palavra, por suas qualidades tímbricas e musicais, de linguagem percussiva. Como o próprio compositor indica na partitura, o músico deve: “'tocar' os

12 "Vinko Globokar, Toucher - Nath Calan". Disponível em https://youtu.be/bpvQKo2BEIY (CALANDRIN, 2015). Acesso 25 fev 2021.

13 "Toucher by Vinko Globokar". Disponível em https://youtu.be/RIPcH7UFfe0 (PercussionCaleb, 2010). Acesso 25 fev 2021. 
textos falados com os instrumentos, como se fossem recitados, usando as mãos para fazer os instrumentos 'falarem'".

Dessa maneira, o compositor propóe aos percussionistas que sejam responsáveis por uma significativa parcela das escolhas performativas para a execução da obra, dando abertura aos elementos acima citados (instrumentos e montagem), e também às questóes teatrais, ligadas à gestualidade, à colocação da voz e à interpretação dos personagens da obra de Brecht.

Para Quitt (2009), as composições de Globokar são possíveis espaços de exposição da liberdade humana. Os instrumentistas precisam estar preparados a assumir riscos e a expor as suas incertezas no ato performativo. O que interessa a Globokar é a performance como uma aventura em si.

Por meio de açóes que vão além dos elementos da prática instrumental comum, o músico também se apresenta fora de seu domínio seguro como especialista. Ao perder sua máscara costumeira, ele não consegue uma nova para colocar em seu lugar (QUITT, 2009, p. 36) ${ }^{14}$.

Nas outras cenas o músico interpreta diferentes personagens e situaçóes que fazem diretamente referência a obra de Brecht e a luta de Galilei por sua liberdade de expressão.

Mais que narrar uma história, essa composição evidencia a interligaçáo entre voz e instrumentos, colocando o percussionista como um performer do corpo. Sendo assim, a narração não é mais importante que o jogo do percussionista e seus meios de produzir uma linguagem percussiva que convença o espectador de sua realidade. Enquanto toca, o músico se apresenta por si mesmo e, comportando-se de uma forma inesperada para o público, estabelece com ele uma relação pessoal, pois se apresenta não apenas como músico mas como pessoa. Segundo Quitt (2009, p. 36), Globokar, em suas obras, gera "sentimentos que vão da alienação ao constrangimento que esta pode despertar, gerando incertezas na plateia, que marcam, ao mesmo tempo, um passo no questionamento sobre seu papel comportamental" 15 .

\section{Mitos Brasileiros (1988) de Ney Rosauro}

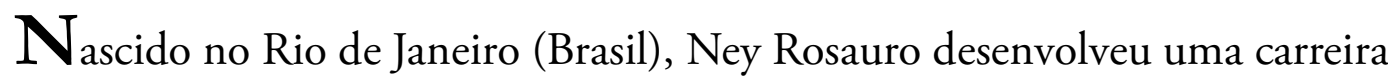
internacional como percussionista, compositor e professor universitário. Como compositor, publicou mais de 100 peças para percussão, bem como diversos métodos. Suas composiçóes são muito conhecidas e foram gravadas por artistas aclamados, como Evelyn Glennie e a London Symphony Orchestra. Seu estilo de escrita autoral: "combina melodias encantadoras com ritmos cativantes [...]. Utiliza os ricos elementos do folclore brasileiro para criar composiçóes estilizadas, cheias de vida e fantasia" (Site do autor ${ }^{16}$ ).

Mitos Brasileiros ${ }^{17}$, de 1988, é um exemplo dessa inspiração do folclore brasileiro. A

$14 \quad$ "Through actions that go beyond the elements of normal instrumental practice, the musician also presents himself outside of his secure domain as a specialist. While losing his accustomed mask, he doesn't get a new one to put on in its place" (Tradução nossa).

15 "The feelings ranging from alienation to embarrassment that this may arouse, causing un-certainty in the audience, simultaneously mark a step towards questioning their behavioural role too" (Tradução nossa). 16 Disponível em: https://www.neyrosauro.com/about/\#bio. Acesso 18 de fev 2021.

17 Sugerimos assistir a explicação do compositor e a performance dos alunos da USP de Ribeirão Preto (2018), disponível em: https://www.youtube.com/watch?v=Y4eC9Kb5vrU (Airton da Percussão, 2018). 
composição, escrita para quatro percussionistas executando uma montagem de percussão múltipla cada um, é dividida em cinco movimentos e cada um leva no título o nome de um personagem folclórico - Curupira, Iara, Saci Perere, Uirapuru e Mula sem Cabeça - que são retratados através de paisagens sonoras, o que nos possibilita remeter ao estilo programático.

Os cinco movimentos retratam diferentes seres mitológicos do folclore brasileiro. Vários instrumentos não usuais são usados para dar a cada movimento uma cor especial, e uma breve abordagem teatral é requerida em alguns pontos. Uma obra cheia de surpresas humoradas e momentos exóticos que irá encantar qualquer audiência (Site do autor ${ }^{18}$ ).

O primeiro movimento, Curupira, traz a agilidade e o perigo do personagem através da indicação de Allegro, dos acentos, das dinâmicas contrastantes e dos compassos compostos. Além disso, intervalos de segundas e terças são encontrados. No Ex. 2, podemos perceber algumas dessas características:

Exemplo 2: Primeiros compassos do movimento Curupira (ROSAURO, 1988).

\section{I) CURUPIRA}

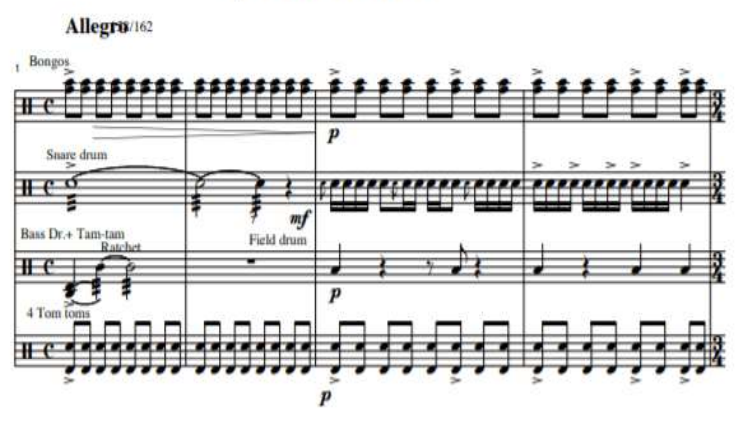

Iara, movimento seguinte, traz a sutileza da personagem das águas através de andamento lento, livre, notas longas e rulos. Os instrumentos utilizados oferecem ao movimento uma atmosfera de água, com a bacia e os copos de vidro, uma atmosfera de trováo, com o thunder sheet (folha de trovão) e uma atmosfera de suspense com o prato suspenso. $\mathrm{O}$ vibrafone e o glockenspiel propóem melodias expressivas, lentas, e, por vezes, repetitivas.

O Saci Pererê, personagem divertido e animado, é o terceiro movimento da obra, onde percebemos instrumentos mais agudos, se comparados aos outros movimentos, e ritmos sincopados e repetidos, como podemos perceber nos bongôs, tom-tons e agogô. Melodias cromáticas também marcam presença no movimento através do vibrafone.

O quarto movimento, Uirapuru, tenta reproduzir o canto de um pássaro com apitos, taças de vidro com água e garrafa de água, além de trazer melodias no xilofone e no glockenspiel. Sua atmosfera é calma e as dinâmicas passeiam entre piano e mesopiano.

Acesso 25 fev 2021. Outra performance que sugerimos assistir, está disponível em: https:/www.youtube.com/ watch?v=aPmvCIetQRs (Round Top Festival Institute, 2012). Acesso 25 fev 2012. Analisando de maneira breve essas duas performances, podemos perceber uma tendência de os percussionistas brasileiros executarem os movimentos de maneira mais fiel aos personagens do folclore brasileiro, por conta da familiaridade aos seus contos e lendas. Isso pode ser percebido através dos andamentos executados, da gestualidade exibida pelos intérpretes, entre outros elementos. Vale ressaltar que esses aspectos náo influenciam na qualidade da execuçáo. 18 "The five movements depict different mythological beings from Brazilian folklore. Several unusual instruments are used to give each movement a special color, and a slightly theatrical approach is required at some points. A work full of humorous surprises and exotic moments which will enchant any audience" (Tradução nossa). Disponível em: https:/www.neyrosauro.com/works/mitos-brasileiros/, último acesso 18 fev. 2021.

ISSN 1516-2737 | e-ISSN 2238-6599 
O último movimento, por sua vez, narra situaçóes com a Mula sem Cabeça, personagem rápido e perigoso. No movimento o andamento é vivo, as dinâmicas crescem rapidamente, os ritmos são sincopados (como podemos perceber no coco, nos tom-tons e no cowbell). Outros instrumentos são utilizados, como o atabaque, a caixa-clara (mais especificamente o field drum), temple-blocks, bumbo, tamborim, entre outros instrumentos, exibindo um final de obra enérgico com diversidades timbrísticas.

Para cada instrumentista do quarteto, o compositor sugere uma lista de instrumentos, obrigando o intérprete a fazer uma montagem de percussão múltipla, onde observamos a necessidade de obedecer algumas condiçôes implícitas. Dentre elas: o espaço do palco disponível para a performance; o espaço entre um músico e outro; o espaço entre um instrumento e o outro; e o espaço necessário para executar os gestos cênicos. Como podemos ver nas figuras a seguir, apesar dessas condiçóes, as montagens podem ser variadas:

Figura 4: Montagem da obra Mitos Brasileiros (1988), por Brice Burton, Julian Loida, David Reinecke, Joseph Kelly (Round Top Festival Institute, 2012) ${ }^{19}$

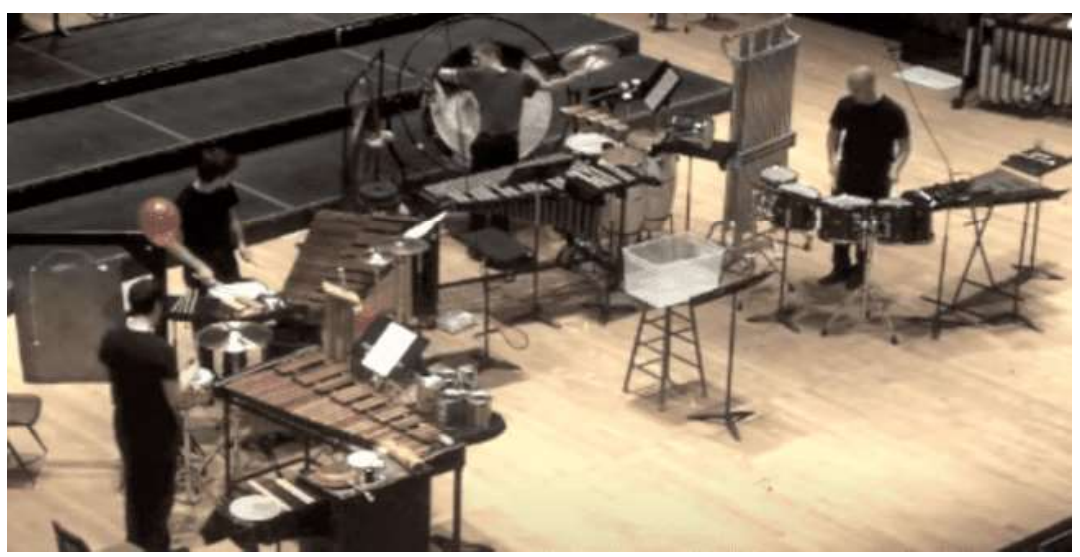

Figura 5: Monta da obra Mitos Brasileiros (1988), pelo Percussion Quartet (thecircle90, 2012) ${ }^{20}$

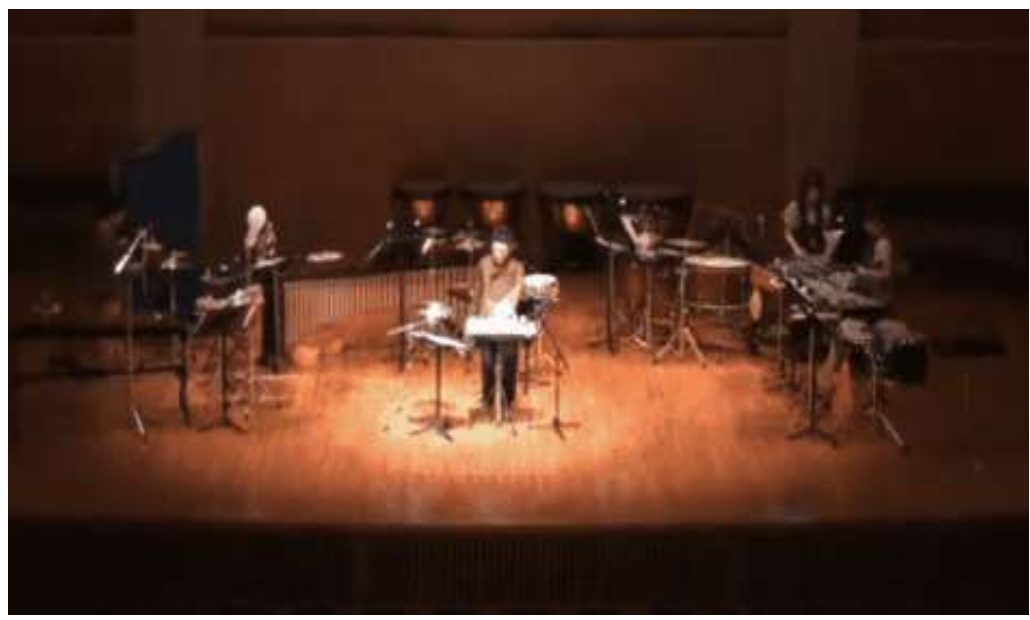

19 A performance pode ser assistida no link a seguir: https://www.youtube.com/watch?v=aPmvCletQRs\&t=29s (Round Top Festival Institute, 2012). Acesso 25 fev 2012.

20 Disponível em: https://www.youtube.com/watch?v=Ww7FEP5cktU (thecircle90, 2012). Acesso 25 fev 2021. 
Figura 6: Montagem da obra Mitos Brasileiros (1988), pelos alunos da USP de Ribeirão Preto (Airton da Percussão, 2018) ${ }^{21}$

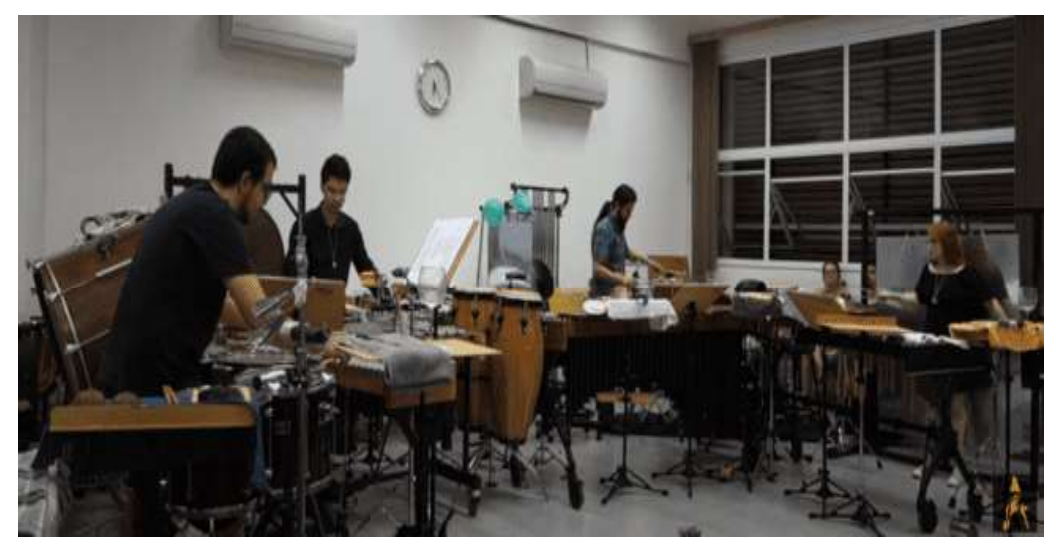

Podemos perceber através das três figuras acima as diferentes possibilidades de montagem, que dependem de diversos aspectos performativos: espaço (palco, entre os músicos, entre os instrumentos, entre outros), escolhas pessoais de cada performer para sua montagem, etc.

Os quatros percussionistas, além de tocar um set de instrumentos percussivos muito variado, usam recursos vocais como os fonemas "sho" (no último movimento) com uma execução grave e o "hiiamm" (no primeiro movimento) aguda. A adoção desses recursos vocais, assim como o fato de os instrumentos ocuparem um espaço extenso, obrigando o musicista a se movimentar para mudar de instrumento, resulta em uma performance animada que permite, além da execuçáo musical, uma experimentaçáo teatral.

\section{A Dois (1992) de Tim Rescala}

Tim Rescala, nascido no Rio de Janeiro em 1961, é um dos compositores mais premiados do Brasil, estudou na Escola de Música da UFRJ e na Escola de Música Villa-Lobos e obteve licenciatura na UNI-RIO, em 1983. Estudou composição, contraponto e arranjo com Han-Joachim Koellreutter. Rescala é conhecido por ser um compositor versátil, escrevendo para cinema, TV, exposiçóes, óperas, musicais, por exemplo. Foi compositor e diretor musical de várias peças de teatro.

Na TV Globo compôs sucessos para novelas dirigidas por Luiz Fernando Carvalho, como Meu Pedacinho do Chão e Velho Chico (Site do autor ${ }^{22}$ ). A relevância do compositor também se estende à música contemporânea escrita no Brasil e no exterior, de 1978 aos dias atuais.

Além de seu trabalho na televisão ele é muito conhecido por compor peças com fortes elementos cênicos, alguns exemplos são A Base (1989), Bravo (1989), Música (1989), Psiu! (1989), A Dois (1992), Romance Policial (1994) e outras mais (ANDRADE, 2008, p.28-45). Rescala, entretanto, compóe em diversas áreas da criação musical, atuando também na música contemporânea e na música popular (OLIVEIRA, 2015, p. 45).

21 Disponível em: https://www.youtube.com/watch?v=Y4eC9Kb5vrU\&t=579s (Airton da Percussão, 2018). Acesso 25 fev 2021.

22 Disponível em: http://timrescala.com.br/br/bio. Acesso em 17 fev 2021. 
A Dois, de 1992, para dois percussionistas, é uma obra relevante para o repertório percussivo cênico brasileiro, utilizando a percussão múltipla, a voz e elementos cênicos. Diversamente da obra de Globokar, que apresentamos no tópico anterior, $A$ Dois entrelaça recursos cênicos teatrais, como a dramaturgia, a atuação, o movimento e a mímica, e recursos musicais, que, juntos, nos aparenta uma narrativa que propóe criticar a relaçáo sexista, através de uma discussão de um casal de homem e mulher na década de 1990. No cotidiano de sua casa, a esposa e o marido discutem sobre que canal assistir na televisão, futebol ou novela. Apesar de encenar um drama, não há cenografia na peça, o cenário é imaginado a partir da ação dramatúrgica dos personagens. Rescala trata de temas, tidos hoje em dia como polêmicos, como a violência doméstica, o machismo, a relação tóxica, com uma tentativa de entrelaçar a música e o teatro de maneira humorada.

Vale ressaltar que esse cotidiano, apesar de ainda comum na sociedade, exemplifica atitudes machistas, sexistas e violentas verbais e físicas, excedendo o ponto de uma relação respeitosa entre duas pessoas, independente do gênero. Falas como: "Larguei os meus estudos, larguei a minha família"; "É só casa, cozinha, casa, criança"; ou "Ai! Você me bateu!" - que são reproduzidas pela personagem mulher; "Não me provoca, olha que eu te bato"; ou "Tudo! Nessa casa eu pago tudo!" - que são as falas do homem - exemplificam essas questões ${ }^{23}$.

Sobre essas questóes, podemos apontar uma significativa discussão e reflexão, acerca desse assunto, no intuito de conscientizar a população no que diz respeito à relaçóes abusivas, algumas dessas questôes são reproduzidas através das falas exemplificadas acima. Importante destacar que, apesar de náo se tratar de um assunto engraçado, a obra e os performers da mesma a conduzem de maneira cômica, arrancando risos dos espectadores.

Cada percussionista interpreta um lado da história, e, em certas ocasiôes, para que haja uma maior ironizaçáo da cena podemos perceber trocas de papéis (a mulher faz a parte do homem e vice versa) ou até dois homens ou duas mulheres executando a obra. A seguir, podemos visualizar três possibilidades: a primeira (Figura 7) percebemos que os papéis da mulher e homens estão sendo, respectivamente, interpretados por uma mulher, Ana Letícia Barros, e um homem, Rodolfo Cardoso; a segunda (Figura 8), os papéis estão sendo interpretados por dois homens, sendo que o papel da mulher está sendo interpretado por Pedro Freira, e do homem por Eliel Espíndola:

Figura 7: Performance de Ana Letícia Barros e Rodolfo Cardoso, em 2002 (RESCALA, 2012) ${ }^{24 .}$

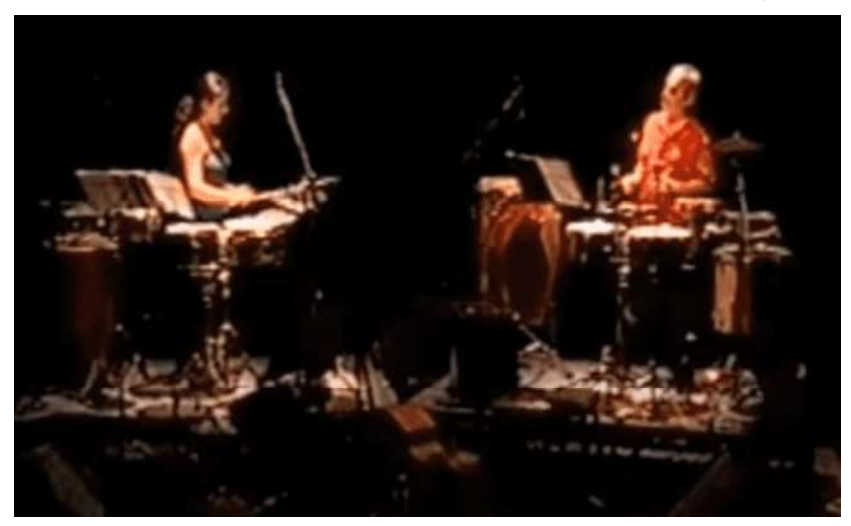

23 Nos furtaremos de um maior aprofundamento, pois não é o objetivo dessa pesquisa. No entanto, acreditamos que esse tema, de extrema importância, poderá ser abordado por outros pesquisadores.

24 Para melhor visualizar, disponível em: https://www.youtube.com/watch?v=9BkpLZLrwNo (RESCALA, 2012). Acesso 25 fev 2021. 
Figura 8: Performance de Pedro Freira e Eliel Espíndola, em 2011 (percumpa ufrn, 2012)25.

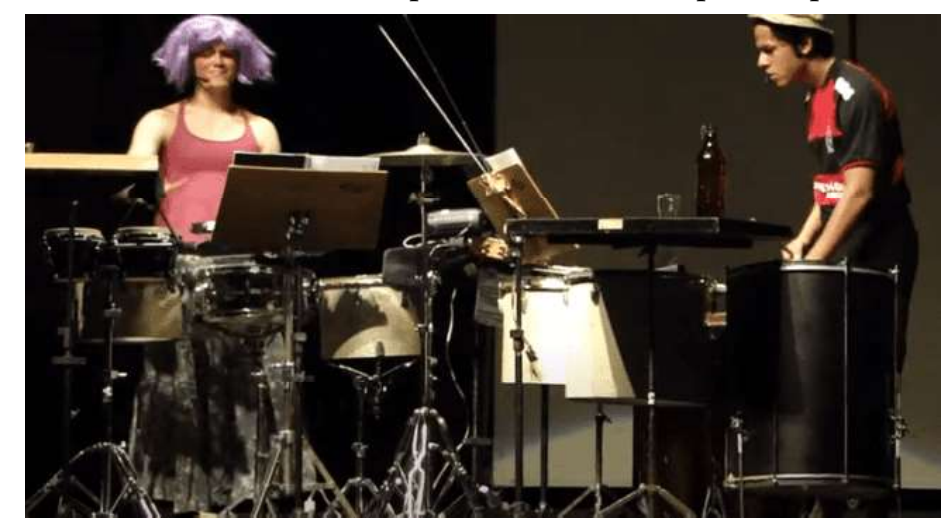

$\mathrm{Na}$ terceira possibilidade percebemos que Aquim Sacramento interpreta a mulher, enquanto Sandra Valenzuela interpreta o homem, escolha que julgamos inusitada, portanto, mais engraçada para o público (Figura 9).

Figura 9: Aquim Sacramento (nome artístico; Almeida) e Sandra Valenzuela interpretando a obra $A$ Dois (1992), em 2013 (Acervo pessoal do autor).

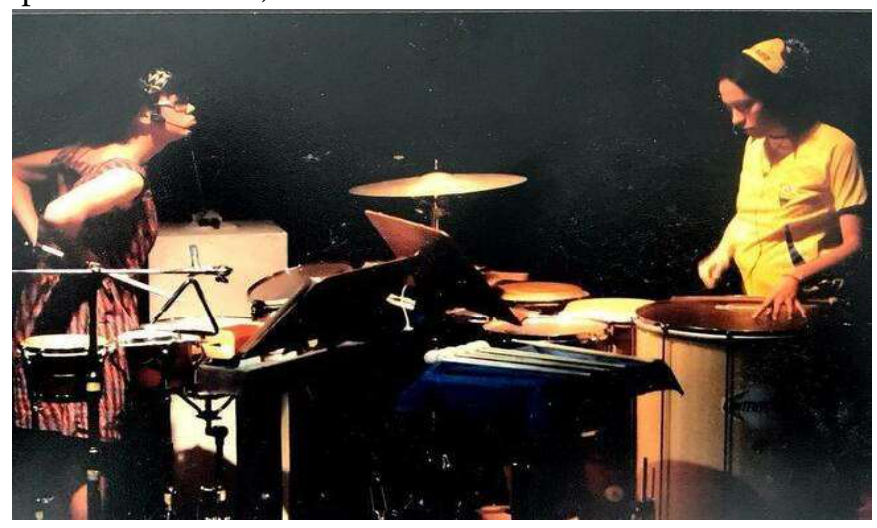

Cada performer utiliza um set de instrumentos percussivos (como podemos ver nas figuras anteriores) que são executados simultaneamente às falas dos personagens, caracterizando como um trabalho de independência técnica e cênica, onde os ritmos da percussão não podem interferir na naturalidade e organicidade da fala. Essa independência e polirritmia podem ser percebidas no compasso que exibimos no Ex. 3.

Exemplo 3: Trecho de A Dois (1992) onde possui polirritmia entre voz e percussão (RESCALA, 1992).

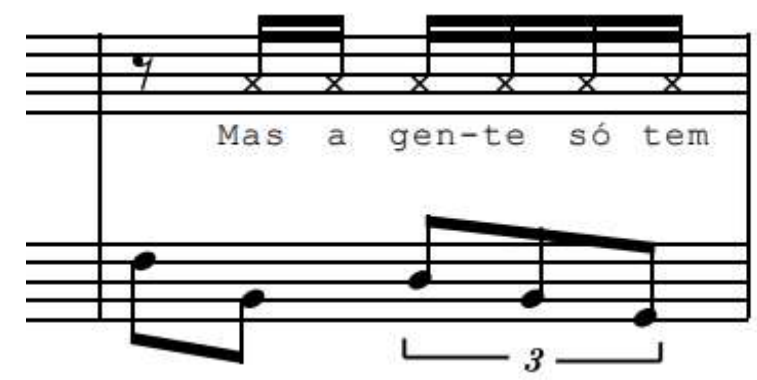

25 Também sugerimos assistir a performance do Duo Percumpá, disponível em: https://www.youtube. com/watch?v=Xd-ThcgquTI (percumpa ufrn, 2012). Acesso 25 fev 2021. 
Mesmo com o intuito de respeitar os ritmos das falas, os intérpretes precisam observar maneiras de executá-las de maneira orgânica, como se estivesse de fato em uma discussáo com alguém, respeitando inclusive os climas sugeridos pelo autor, no decorrer das seçóes: "monotonia", "divergências", "amor", por exemplo.

Em segundo plano (em dinâmica inferior), o percussionista precisa tocar em seu set de instrumentos o ritmo especificado pelo compositor. Esses ritmos formam polirritmias com os ritmos da fala. No entanto, se isolarmos a parte percussiva, podemos perceber ritmos simples que são distribuídos entre mais de 15 timbres sugeridos pelo compositor.

Os instrumentos e timbres, especificados pelo compositor (Ex. 4), acompanham as seçôes da obra, podendo ouvir em partes calmas woodblocks (blocos de madeira), por exemplo, e em outras mais agitadas o prato suspenso. Podemos associar a utilizaçáo dos instrumentos à produçáo de trilhas sonoras, onde ouvimos sons que reproduzem o que está sendo falado ou sentido pelos personagens, prática muito vista em rádio e televisão.

Essa obra oferece diversas possibilidades interpretativas, como percebemos nas performances citadas anteriormente, pois oferece aos percussionistas significativas possibilidades de execução da mesma, tanto em elementos cênicos e da voz, quanto em elementos percussivos, escolha de timbre dos instrumentos e montagem do set instrumental.

Exemplo 4: Bula da obra A Dois (1992) especificando timbres, baquetas e instrumentos (RESCALA, 1992)

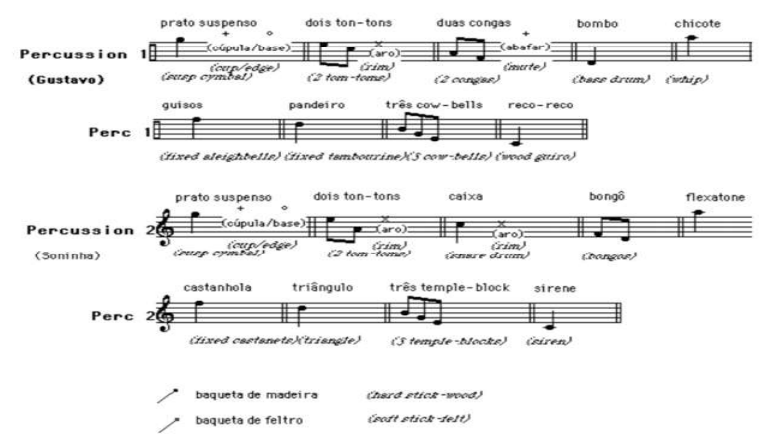

\section{Reflexôes em forma de conclusão}

$\mathbf{E}_{\text {ste trabalho abordou interseçôes entre a música cênica, a utilização da voz }}$ de maneiras diversas e a percussão múltipla, muito presentes no repertório escrito para percussão do século XX aos dias atuais. Isso pode ser percebido em diversas formaçóes, solo, música de câmara ou grupo de percussáo.

Essa aliança pode ser vista como uma consequência de diversos movimentos que foram iniciados no século XX, como o Movimento Futurista, a Revolução Industrial, entre outros. Esses movimentos deram aos compositores da época novos estímulos e novas inspiraçôes para utilizar os instrumentos de percussão de maneira inovadora, para o momento.

Esse repertório se tornou um vasto campo de experimentaçáo, principalmente quando percebemos esses três elementos: música cênica, voz e percussão múltipla.

Entendemos ser de extrema importância refletir sobre essas interseçôes no repertório percussivo para que esse olhar sobre esses objetos em união seja difundido na comunidade musical, abordando obras relevantes do repertório e algumas de suas características mais marcantes. 
Almejamos com esse trabalho estimular novas pesquisas que abordem interseçóes desses objetos pesquisados neste artigo. Acreditamos ser de grande significância a ampliação do repertório performativo e reflexivo do músico percussionista no seu processo de aprendizado e performance.

\section{Referências}

FACCHIN, Guido. Le percussioni: storia e tecnica esecutiva nella musica classica, contemporanea, etnica e d'avanguardia. Varese: Zecchini Editore, 2014. 1200p.

GLUSBERG, Jorge. A Arte da Performance. 2. ed. São Paulo: Editora Perspectiva, 2013. $145 \mathrm{p}$.

KLINGENDER, Francis Donald. Arte e rivoluzione industriale. Torino: Giulio Einaudi Editore, 1972. 292p.

MARTINS, Natali Calandrin. Música cênica no repertório de percussáo contemporâneo: estudo interpretativo de Toucher, de Vinko Globokar. Dissertação de Mestrado. Universidade Estadual de Campinas, Instituto de Artes, 2015. Campinas: UNICAMP, 2015. 120p.

NAVAS, Loma Monica Rocio. A atuaçáo multifacetada do percussionista: Desafios de performance em três obras para percussão solo. Dissertação de Mestrado. Universidade Federal de Minas Gerais, Escola de Música, 2016. Belo Horizonte: UFMG, 2016. 105p.

OLIVEIRA, Mateus Espinha. A presença de instrumentos de percussão da música popular na música de concerto: estudo e performance de Íris para berimbau solo, de Alexandre Lunsqui; Concerto para Pandeiro, de Tim Rescala; e Boreal III para chocalhos e eletrônica, de Guilherme Bertissolo. Dissertação de Mestrado. Universidade Federal de Minas Gerais, Escola de Música 2015. Belo Horizonte: UFMG, 2015. 118p.

QUITT, Roland. Globokar and the theatre. Em Vinko Globokar, Munchen: Ricordi, 2009. 34-42p.

RICORDI. Vinko Globokar. Munchen: Ricordi, 2009. 79p.

RUSSOLO, Luigi. L’arte dei rumori. Milano: Edizioni Futuriste di Poesia, 1916. 93p.

SCHAFER, R. Murray. A afinação do mundo: uma exploração pioneira pela história passada e pelo atual estado do mais negligenciado aspecto do nosso ambiente: a paisagem sonora. São Paulo: UNESP, 2001. 381p.

TULLIO, Eduardo Fraga. O Grupo do Brooklin: Semente da Percussão Contemporânea no Brasil. Tese de Doutorado. Universidade de Aveiro, Escola de Música, 2014. Portugal: UA, 2014. 234p. 
TULLIO, Eduardo Fraga; SULPÍCIO, Eliana. Grupo de Percussão: breve histórico e primeiras performances no Brasil de 1964 a 1980. Vórtex, Curitiba, v.4, n.3, 2016, p.1-18.

ZORZETTO, Paulo. Percussáo e voz na Música-Teatro em três obras solo: proposta de um Modelo Vocal para Percussionistas. Dissertação de Mestrado. Universidade Estadual Paulista "Julio de Mesquita Filho", Instituto de Artes, 2016. São Paulo: UNESP, 2016. 182p.

Referências de site

RESCALA, Tim. Website. Disponível em: http://timrescala.com.br/br/bio. Acesso em 26 fev 2021.

ROSAURO, Ney. Website. Disponível em: https://www.neyrosauro.com/about/\#bio. Acesso em 18 fev 2021.

ROSAURO, Ney. Website. Disponível em: https://www.neyrosauro.com/works/mitos-brasileiros/. Acesso em 18 fev 2021.

Referências de vídeo

AIRTON DA PERCUSSÃO. Concerto MITOS BRASILEIROS - composição Ney Rosauro. Vídeo de 21 minutos e 18 segundos. Postado no YouTube por Airton da Percussão em 8 de setembro, 2018. Disponível em: <https://www.youtube.com/ watch?v=Y4eC9Kb5vrU>. Acesso em 25 fev 2021.

CALANDRIN, Natali. Vinko Globokar, Toucher - Nath Calan. Vídeo de 8 minutos. Postado no YouTube por Natali Calandrin em 21 de setembro, 2015. Disponível em: <https://www.youtube.com/watch?v=bpvQKo2BEIY>. Acesso em 25 fev 2021.

MORIN, Emillie. Jean-Pierre Drouet performing Globokar and Aperghis. Vídeo de 19 minutos e 45 segundos. Postado no YouTube por Emillie Morin em 16 de junho, 2016. Disponível em: <https://www.youtube.com/watch?v=XbsXAgIuTm0\&$\mathrm{t}=360 \mathrm{~s}>$. Acesso em $25 \mathrm{fev} 2021$.

PERCUMPA, Ufrn. PERCUMPÁ - UFRN “A Dois” (Tim Rescala) Eliel Espindola e Pedro Freire 2011. Vídeo de 10 minutos e 22 segundos. Postado no YouTube por percumpa ufrn em 5 de abril, 2012. Disponível em: <https://www.youtube.com/ watch?v=Xd-ThcgquTI $>$. Acesso em 25 fev 2021.

PERCUSSION, Caleb. Toucher by Vinko Globokar. Vídeo de 9 minutos e 56 segundos. Postado no YouTube por PercussionCaleb em 17 de fevereiro, 2010. Disponível em: <https://www.youtube.com/watch?v=RlPcH7UFfe0>. Acesso em 25 fev 2021.

RESCALA, Tim. A Dois (1992) Tim Rescala. Vídeo de 8 minutos e 29 segundos. Postado no YouTube por Tim Rescala em 23 de fevereiro, 2012. Disponível em: <https:// www.youtube.com/watch?v=9BkpLZLrwNo $>$. Acesso em $25 \mathrm{de} \mathrm{fev} 2021$. 
Round Top Festival Institute. Ney Rosauro Mitos Brasileiro (Brazilian Myths). Vídeo de 18 minutos e 41 segundos. Postado no YouTube por Round Top Festival Institute em 25 de julho, 2012. Disponível em: < https://www.youtube.com/watch?v=aPmvCletQRs>. Acesso em 25 fev 2021.

THECIRCLE90. MitosBrasileiros (Brazilian Myths) - Ney Rosauro. Vídeo de 20 minutos e 21 segundos. Postado no YouTube por thecircle90 em 12 de abril, 2012. Disponível em: <https://www.youtube.com/watch?v=Ww7FEP5cktU>. Acesso em 25 fev 2021.

\section{Referências de partitura}

GLOBOKAR, Vinko. Toucher: für einen Schlagzeuger. Frankfurt; New York: H. Litolff's Verlag/C.F. Peters, 1978.

RESCALA, Tim. A dois. 1992.

ROSAURO, Ney. Mitos Brasileiros. Santa Maria - RS: Propercussão, 1988. 